\title{
Desempenho Ortográfico e Habilidades de Produção Textual em Diferentes Condições de Solicitação
}

\author{
Gislaine Gasparin Nobile ${ }^{1}$ \\ Sylvia Domingos Barrera \\ Universidade de São Paulo
}

\begin{abstract}
RESUMO - Este estudo teve como objetivos investigar as relações entre conhecimento ortográfico e produção escrita de textos, além de analisar em que medida diferentes condições de produção afetam a qualidade dos textos narrativos. Participaram do estudo 72 alunos do $5^{\circ}$. ano do Ensino Fundamental de uma escola pública. Os dados foram coletados pela aplicação de um ditado e por três produções de texto: livre, a partir de sequência de figuras e reconto. Os resultados mostraram que os alunos possuem conhecimento precário da ortografia, sendo os erros mais frequentes aqueles envolvendo regularidades contextuais e morfossintáticas, além dos casos irregulares. Os textos mais elaborados foram aqueles produzidos a partir do reconto. Obtevese correlação positiva moderada, mas estatisticamente significativa entre escrever ortograficamente correto e produzir textos mais elaborados.
\end{abstract}

Palavras-chave: ortografia, linguagem escrita, metalinguística

\section{Orthographic Knowledge and the Ability to Produce Texts in Different Production Conditions}

\begin{abstract}
This study aimed to investigate the relationship between orthographic knowledge and writing texts, and analyze whether different production conditions affect the quality of narrative texts. Study participants were 72 students in the 5 th year of Public Elementary Education. Data were collected by applying a dictation and by the writing of texts in three production situations: free theme, from a sequence of figures and retelling. The results showed that students have a poor knowledge of spelling, being the most frequent errors those involving contextual and morphosyntactic rules, besides the irregular cases. The more elaborated texts were those produced from the retelling condition. A moderate but statistically significant positive correlation was obtained between spelling correctly and writing more elaborated texts.
\end{abstract}

Keywords: orthography, written language; metalinguistics

Nos últimos 30 anos, a Psicologia Cognitiva tem oferecido relevantes contribuições para a compreensão dos processos psicológicos envolvidos na aprendizagem da leitura e escrita. Ressalta-se a importância das habilidades metalinguísticas, uma vez que essa abordagem considera a reflexão sobre a linguagem oral como aspecto indispensável para a aprendizagem da linguagem escrita (Maluf \& CardosoMartins, 2013). Entre essas habilidades, destacam-se, na aprendizagem do sistema de escrita alfabética e de suas regras ortográficas, a consciência fonológica - capacidade de análise da língua oral de acordo com suas unidades sonoras constituintes (Barrera \& Maluf, 2003) e a consciência morfológica - capacidade de análise e reflexão sobre as unidades de significado (morfemas) que compõem as palavras (Correa, 2009). Outra habilidade metalinguística importante, mais diretamente relacionada à escrita de textos, é a consciência metatextual, na qual o objeto de análise e reflexão é o texto, sua organização e suas propriedades formais (Spinillo, 2009).

Após atingir o nível de escrita alfabética, um novo desafio será enfrentado pelo aprendiz: dominar o sistema ortográfico.

1 Endereço para corrspondência: Avenida dos Bandeirantes, 3.900, Bairro Monte Alegre, Ribeirão Preto, SP, Brasil. CEP: 14.040-901. E-mail: gislainenobile@yahoo.com.br
Entende-se que os sistemas alfabético e ortográfico não são independentes, mas interrelacionados, já que, ao atingir o nível alfabético de escrita, algumas regularidades do sistema ortográfico já foram dominadas conjuntamente.

De acordo com Morais, Leite e Kolinsky (2013), “o código ortográfico de uma língua é o conjunto das regras, simples e complexas, de correspondência grafofonológica ou fonográfica, historicamente constituído para a língua em questão" (p.22). A criação e o uso das convenções ortográficas permite diferenciar a grafia de palavras com sons idênticos, porém significados diferentes - como no caso das palavras concerto e conserto - permitindo também uma unificação para lidar com as variedades dialetais, o que não significa afirmar que existem formas de pronúncia mais adequadas que outras, mas uma norma para a escrita correta e compreensível (Morais, 2007a).

Escrever ortograficamente correto não é um processo passivo, mas deve ser visto como um processo de construção, sendo assim não é também um conhecimento espontâneo ou exclusivamente de regras a serem memorizadas e/ou treinadas, "dada a sua natureza de convenção social, o conhecimento ortográfico é algo que a criança não pode descobrir sozinha, sem ajuda" (Morais, 2008, p.20). E um sistema cuja aprendizagem envolve reflexão e compreensão, a qual se inicia com o domínio do princípio alfabético, 
passando então para a tentativa de grafar foneticamente todos os fonemas que compõem uma determinada palavra, até a percepção de que a escrita, em muitos casos, não é uma transcrição fiel da fala, surgindo as dificuldades ou dúvidas na utilização do sistema, sendo que as informações que faltarem para uma escrita correta serão assimiladas gradualmente (Leal \& Roazzi, 2007).

É possível considerar que os aprendizes, mesmo com explicações simples, sem o uso de terminologias técnicas, conseguem compreender e generalizar certas regras ortográficas e tentam aplicá-las em vários contextos de escrita, pois "tem-se visto que as crianças podem se beneficiar de um ensino que lhes ajuda a compreender e formular com suas próprias palavras as regras que estão aprendendo" (Morais, 2007b, p.95). Essa reflexão pode se dar por meio do desenvolvimento da consciência morfossintática, como discutido por Correa (2009), enfatizando-se que a análise morfológica prediz o desempenho na escrita de palavras que se apoiam em regularidades morfossintáticas. Com isso, as normas ortográficas "são de natureza gerativa e assim sendo a criança que tem domínio de uma regra deveria, em princípio, ser capaz de escrever corretamente tanto palavras reais quanto inventadas" (Rego \& Buarque, 2007, p.25), além de também conseguir realizar transgressões ortográficas intencionais, como sugerem os resultados obtidos por Morais (2008), Santos e Barrera (2012).

Segundo Morais (2008), a norma ortográfica que utilizamos é organizada com base em diferentes tipos de regularidades (comportando também algum grau de irregularidade). Nos casos de regularidades diretas, há uma relação biunívoca entre letra-som, como no caso das grafias envolvendo as letras P, B, T, F, V, D. Nos casos de regularidades contextuais, é o contexto que vai definir a letra a ser escrita. Por esse motivo, torna-se necessário observar, na escrita de uma determinada palavra, qual letra vem antes ou depois (como no uso do $\mathrm{M}$ ou N, R ou RR, C ou QU, G ou GU) bem como qual a tonicidade da palavra (principalmente para as terminações em $\mathrm{O}$ ou U; E ou I). Já nos casos de regularidades morfológico-gramaticais, a grafia está ligada à categoria gramatical da palavra e/ou à sua formação, envolvendo os morfemas e sufixos. Dessa forma, é necessário conhecer algumas informações, como a de que os adjetivos que indicam o local de nascimento se grafam com o sufixo ESA, já os substantivos derivados, terminam com EZA. Nos casos irregulares, geralmente relacionados à etimologia da palavra, como o próprio termo diz, não há regras. Com isso é necessária a utilização do dicionário e/ou recorrer à memorização, no caso de palavras mais frequentes.

$\mathrm{Na}$ trajetória dos estudos sobre o conhecimento da ortografia, alguns autores têm se dedicado a analisar os erros ortográficos apresentados pelos alunos em tarefas de ditado e produção de textos. Tipologias a respeito desses erros podem ser encontradas nos trabalhos de Carraher (1985), Nunes (1992), Zorzi (1998) e Guimarães (2003, 2005). É importante salientar que, muitas vezes, as categorias propostas por esses autores se sobrepõem e/ou se complementam. Com base nos estudos desses pesquisadores, elaboramos a lista a seguir, cujas categorias foram usadas na análise dos erros ortográficos obtidos na presente pesquisa: (a) Transcrição da fala: ocorrem quando o aluno escreve da forma como fala.
P. ex.: papeu (papel), mininu (menino); (b) Supercorreção: ocorrem quando o aluno tenta corrigir os erros de transcrição da fala. P. ex.: pedil (pediu), tenes (tênis); (c) Regras contextuais: ocorrem quando o aluno deixa de considerar a posição de uma letra em relação a outras. P. ex.: canpo (campo), gitarra (guitarra); (d) Marcação da nasalização: caracterizam-se pela não diferenciação entre vogais nasais e orais ou pela marcação inadequada da nasalização. P. ex.: iteiro (inteiro), elefãote (elefante); (e) Sílabas complexas: ocorrem na escrita de sílabas com estruturas diferentes, que não sejam consoante-vogal. P. ex.: boboleta (borboleta), baço (braço). A utilização inadequada dos dígrafos NH, LH e CH também pode ser classificada nesta categoria. P. ex.: coelo (coelho); (f) Troca de letras: caracterizam-se pela escolha da letra errada para representar determinado som. P. ex.: paixe (peixe), discrimidativa (discriminativa); (g) Trocas surdas/ sonoras: outras trocas frequentes são entre $p / b, t / d, c / g, f / v$ ou seja, trocas entre fonemas que apresentam o mesmo ponto e modo de articulação, porém cuja diferença está na vibração ou não das cordas vocais durante a emissão dos mesmos. P. ex.: evetivo (efetivo), vormiga (formiga); (h) Representação Múltipla: dizem respeito às situações nas quais um mesmo som pode ser escrito por várias letras e/ou o inverso, devido a motivações etimológicas ou morfossintáticas. P. ex.: sinco (cinco); belesa (beleza); (i) Acréscimo de letras: alterações ortográficas devido ao acréscimo de letras nas palavras, aparentemente sem motivo explicativo. P. ex.: sorturno (soturno), ajoaizar (ajuizar); (j) Ausência de letras: grafia incompleta das palavras, em função da omissão de uma letra. P. ex.: coletiviade (coletividade), impetosidade (impetuosidade).

Vários estudos sobre as competências cognitivas envolvidas na aprendizagem da linguagem escrita têm enfatizado o papel das habilidades metalinguísticas. Para Maluf e Gombert (2008), o termo metalinguístico, "referese às capacidades de reflexão e autocontrole intencional dos tratamentos lingüísticos" (p.125), distinguindo-se assim das primeiras habilidades que a criança manifesta, de ordem epilinguística, as quais referem-se aos conhecimentos linguísticos implícitos, adquiridos espontaneamente, não resultantes de controle consciente, mas da interação do indivíduo com o meio social.

Entre as habilidades metalinguísticas, algumas parecem estar mais diretamente relacionadas à aquisição do sistema de escrita em seus aspectos alfabético e ortográfico enquanto outras estariam mais relacionadas à produção de texto. O estudo de Rego e Buarque (1997) indica que a aquisição das regras contextuais seria facilitada pelo desenvolvimento da consciência fonológica. Também o estudo de Guimarães (2003) obteve evidências de que as dificuldades em leitura e escrita de palavras estão relacionadas diretamente a problemas de natureza metafonológica. Já Queiroga, Lins e Pereira (2006) identificaram um efeito preditor do conhecimento morfossintático em relação à grafia correta das palavras. Tais dados permitiram às autoras observarem que um ensino que privilegie a compreensão dos conhecimentos morfológicos e sintáticos da língua pode favorecer o processo de apropriação da ortografia, pois possibilita maior compreensão dos processos de formação das palavras. 
No que se refere às habilidades de produção textual, considerando prioritariamente, nesse estudo, a elaboração narrativa de histórias, torna-se fundamental considerar o conceito de consciência metatextual, já que essa habilidade pode favorecer o desenvolvimento da compreensão e a utilização de um esquema narrativo, indispensável para a produção escrita de histórias. A consciência metatextual diz respeito a uma terminologia introduzida por Gombert (1992) para se referir a uma habilidade metalinguística na qual a unidade de análise e reflexão é o texto, ou seja, o foco está em sua estrutura, partes constituintes, convenções e marcadores também denominadas relações intralinguísticas. Inicialmente a criança possui um desenvolvimento epilinguístico a respeito de algumas estruturas textuais (aprendizagens informais sobre, por exemplo, o conteúdo e função do texto). Posteriormente, sua reflexão sobre o texto tende a aumentar, como ocorre também com as outras habilidades metalinguísticas, direcionando-se para uma análise intencional, que reconhece no texto suas partes, gêneros e estruturas, além de possibilitar explicitações verbais e justificativas quando essa consciência está em análise.

No estudo de Albuquerque e Spinillo (1998), 63 crianças, divididas em três grupos de escolaridade - pré-escolares, $1^{\text {a }}$ e $3^{\text {a }}$ série -, deveriam julgar se um texto estava completo ou incompleto, justificando suas respostas. Foram investigados os critérios adotados, tendo os resultados indicado diferenças entre as séries, o que sugere a influência da alfabetização na progressão da consciência textual, além de ser o gênero um importante recurso para a justificativa dos critérios adotados.

De acordo com Spinillo (2009), as funções e o conteúdo do texto podem ser aprendidos informalmente em situações cotidianas, mas a estrutura textual, a organização e as convenções linguísticas necessitam de aprendizagem formal, escolar, envolvendo controle e reflexão, ou seja, um comportamento metalinguístico sobre o texto. A atividade metatextual exige um maior nível de abstração, sendo alcançada por meio do ensino intencional, ou seja, da aprendizagem formal explícita.

De forma geral, a análise do texto remete à noção de gênero textual, o qual diz respeito aos componentes e particularidades formais que permitem diferenciar se um texto é narrativo, dissertativo, poético ou jornalístico. Sabe-se que o gênero mais trabalhado nas escolas, principalmente no ensino fundamental, é o narrativo, por meio de histórias, o qual apresenta princípios de constituição bem delimitados: o início é composto pela descrição da cena e personagens; o desenvolvimento envolve tramas e uma situação-problema; já o final comporta o desfecho e a resolução da situaçãoproblema (Spinillo \& Martins,1997).

Resultados de pesquisas demonstram que os conhecimentos a respeito da estrutura do gênero narrativo desenvolvem-se anteriormente àqueles relativos ao gênero expositivo (Berman, 2008; Babayigit \& Stainthorp, 2011) provavelmente devido à maior experiência das crianças como ouvintes de histórias, tanto no contexto familiar como escolar. Assim, as atividades referentes à produção textual propostas nessa pesquisa inserem-se no gênero narrativo e, a partir do mesmo, Lins e Silva e Spinillo (2000) propuseram as seguintes categorias, as quais permitem avaliar o domínio da estrutura narrativa de textos e também foram utilizadas na análise dos dados desta pesquisa: (a) Categoria I: nãohistórias - textos constituídos por palavras, frases, relatos e/ou descrições de ações; (b) Categoria II: introdução da cena e/ou personagens - uso de marcadores linguísticos convencionais, tais como "era uma vez..."; (c) Categoria III: além da introdução da cena e dos personagens, há o relato de uma ação que sugere um esboço de uma situação-problema; (d) Categoria IV: semelhante à anterior, apresentando tentativa(s) de resolução da situação-problema, estando o desfecho ausente; (e) Categoria V: o desfecho está presente, mas não é explicitado como a situação-problema foi resolvida; (f) Categoria VI: histórias completas com uma estrutura narrativa elaborada.

Alguns estudos também têm se dedicado a comparar a qualidade de textos produzidos a partir de diferentes condições de solicitação. Na pesquisa de Lins e Silva e Spinillo (2000), foi analisado o grau de domínio da estrutura narrativa de produções de texto feitas por 80 alunos de sete a dez anos de uma escola particular, em quatro condições distintas: (a) produção livre; (b) produção oral/escrita (história feita oralmente, posteriormente era solicitada a escrita dessa mesma história); (c) produção a partir de uma sequência de gravuras; (d) produção escrita a partir de uma história lida. Verificou-se que as produções mais elaboradas foram feitas nas condições c e d. As histórias das crianças das séries mais adiantadas foram mais elaboradas em todas as condições, o que indicou que, mesmo após a alfabetização, os anos de escolarização contribuem para o desenvolvimento da escrita de histórias.

Resultados semelhantes foram encontrados no estudo de Pessoa, Correa e Spinillo (2010), que investigaram o efeito das condições de produção - livre e reprodução escrita -, sobre o estabelecimento da coerência na escrita de histórias em 108 alunos que cursavam o $2^{\circ} \mathrm{e} 3^{\circ}$ ano do ensino fundamental. Os alunos do $3^{\circ}$ ano produziram narrativas mais complexas, indicando a escolaridade como fator de maior influência na produção escrita de história. Também foi observado que a condição de reprodução propiciou a escrita de textos mais coerentes e elaborados para a maioria dos participantes, mas não para todos. As autoras sugerem que a sensibilidade ao contexto de produção estaria relacionada ao grau de domínio de um esquema narrativo de histórias, sendo que os alunos com pouco domínio desse esquema não se beneficiariam do modelo de texto oferecido, enquanto aqueles com elevado conhecimento da estrutura narrativa, prescindiriam do oferecimento do modelo.

$\mathrm{Na}$ literatura científica, há poucos estudos abordando a relação entre conhecimento ortográfico e produção escrita de textos. No estudo de Connelly, Dockrell, Valter e Critten (2012), realizado com 99 alunos do ensino fundamental, o desempenho ortográfico foi um preditor significativo da qualidade dos textos escritos. Já o estudo longitudinal de Babayigit e Stainthorp (2011), realizado com 103 alunos de $2^{\circ}$ e $4^{\circ}$ anos do Ensino Fundamental, encontrou correlações moderadas entre habilidades ortográficas e de escrita de textos narrativos apenas na primeira etapa do estudo, sendo que o desempenho ortográfico apresentou pequeno poder explicativo para dar conta das diferenças observadas nas habilidades de produção de texto no final da pesquisa. 
No Brasil, também encontramos poucas pesquisas sobre o tema. No estudo de Barrera e Nobile (2010), realizado com 36 estudantes com dificuldades de aprendizagem, com idade variando entre 9 e 15 anos, alunos de $2^{\mathrm{a}}$ à $8^{\mathrm{a}}$ série do ensino fundamental de escolas públicas, verificou-se que as habilidades de compreensão em leitura mostraramse associadas às competências ortográficas bem como às habilidades de produção textual, porém estas não apresentaram associação significativa entre si.

Já o estudo de Souza e Correa (2007) investigou se a reprodução escrita de um texto conhecido facilitaria o desempenho ortográfico de alunos da $1^{\mathrm{a}}$ e $2^{\mathrm{a}}$ séries do ensino fundamental. Para isso, foram analisadas histórias escritas em dois contextos de produção: a reprodução de uma história conhecida e a escrita livre. Os resultados mostraram que o contexto de produção não influenciou o desempenho ortográfico das crianças em termos do número de erros cometidos, sendo a escolaridade o fator que mais influenciou a ortografia. Entretanto, alguns tipos de erros ortográficos mostraram-se sensíveis aos diferentes contextos de produção, sendo que as transgressões de maior frequência ocorridas na reprodução foram relacionadas às irregularidades da língua, às regularidades morfossintáticas e à acentuação, enquanto que, no contexto de escrita livre, observou-se maior incidência de erros para as regularidades contextuais, trocas de letras e hipercorreção.

Dessa forma, considerando os poucos estudos sobre o tema e as divergências nos padrões de resultados obtidos, além da relevância de se compreender mais a complexa aquisição dos conhecimentos envolvidos na aprendizagem da escrita, este estudo teve como objetivos verificar se as habilidades ortográficas estão relacionadas com a qualidade das produções textuais e se há diferenças no desempenho na produção de textos narrativos em função de variações nas condições de solicitação: produção livre, a partir de sequência de figuras e reescrita (reconto) de história.

\section{Método}

\section{Participantes}

Participaram da pesquisa os alunos de três turmas de $5^{\circ}$ ano de uma escola pública de ensino fundamental, situada na região central de um município de grande porte do interior do Estado de São Paulo. A escola atende predominantemente a alunos da classe socioeconômica média e média baixa, porém recentemente, devido a um processo de "desfavelização" ocorrido no município, passou a atender também uma clientela bem mais carente no que se refere às condições socioeconômicas. A amostra foi constituída por 72 alunos: 44 do sexo feminino e 28 do sexo masculino, com idade média de 9,5 anos $(D P=0,58)$.

\section{Instrumentos e Procedimentos de Coleta e Análise dos Dados}

Para avaliar o conhecimento ortográfico dos participantes, foi utilizado o subteste de escrita do Teste de Desempenho Escolar (TDE), elaborado por Stein (1994), o qual é composto por uma tarefa de ditado de 34 palavras, contendo diversos graus de dificuldades ortográficas. A classificação dos tipos de erros ortográficos foi realizada segundo a tipologia apresentada na introdução deste estudo e analisada por dois juízes independentes, alcançando um nível de concordância de $90 \%$; os outros $10 \%$ foram classificados por meio de avaliação conjunta de ambos os juízes. A partir das 34 palavras que compõem o TDE, foram calculados o total de erros (isso implica afirmar que a escrita de uma palavra pode conter mais de um erro ortográfico) e o total de palavras escritas corretamente.

Para a obtenção dos dados referentes à produção textual, a coleta ocorreu com três métodos diferentes: (a) uma produção sobre tema livre; (b) uma produção a partir das figuras de uma história em quadrinhos do personagem Snoopy, da qual foram retiradas propositalmente as falas (balões), sendo solicitado aos participantes escreverem uma história de acordo com a sequência das figuras; (c) uma produção após os participantes ouvirem a leitura da história "O Lobisomem", feita pela pesquisadora, sendo, posteriormente, solicitado aos participantes realizarem a escrita da mesma (reconto). A sequência das produções se apresentou nessa ordem, para evitar interferências na produção livre.

As análises das produções de texto foram realizadas a partir das categorias já apresentadas, ressaltando-se que a categoria $\mathrm{V}$ (o desfecho está presente, mas não é explicitado como a situação-problema foi resolvida) foi modificada para: histórias quase completas devido à ausência de informações ou partes importantes da história, tanto no desenvolvimento da situação-problema como no desfecho, mas não impedem a compreensão geral da mesma. Essa modificação tornou-se necessária para que a categoria correspondesse mais fielmente à estrutura narrativa apresentada em algumas das produções coletadas. Às categorias I a VI foram atribuídos pontos de 1 a 6, ou seja, quanto maior a elaboração do texto, maior a pontuação. As produções de texto foram analisadas por dois juízes independentes, obtendo um nível de concordância de $87 \%$; a classificação dos outros $13 \%$ se deu por avaliação conjunta, obtendo-se consenso entre os juízes.

As atividades previstas para a coleta de dados foram aplicadas pela pesquisadora, nas próprias classes, em horário normal de aula, sendo que o intervalo da aplicação de uma atividade para a outra foi de uma semana. O dia e horário da aplicação foram agendados previamente com as professoras. Na primeira semana, foi aplicado o ditado do TDE e, nas três semanas seguintes, foram realizadas as produções de texto. Não houve limite de folhas ou de tempo para a realização das produções. Todas as atividades foram realizadas coletivamente.

\section{Procedimentos Éticos}

O projeto de pesquisa foi aprovado por Comitê de Ética em Pesquisa, de acordo com o processo $n^{\circ}$ 629/2011 - 
2011.1.2773.59.0, tendo seguido os preceitos da Resolução 196/96 do Conselho Nacional de Saúde.

\section{Resultados}

Os resultados foram analisados a partir de testes estatísticos não paramétricos, tendo em vista que uma análise preliminar dos mesmos, utilizando o Teste de KolmogorovSmirnov, rejeitou a hipótese de normalidade dos dados para todas as variáveis pesquisadas: erros ortográficos $(D=0,169$; $p<0,001)$, produção livre $(D=0,190 ; p<0,001)$, produção a partir de figuras $(D=0,179 ; p<0,001)$, e produção a partir do reconto de história $(D=0,217 ; p<0,001)$.

Para verificar se haveria diferenças significativas de desempenho entre os participantes das três classes - tanto em termos de conhecimento ortográfico quanto nas habilidades de produção de texto -, foi aplicado o Teste de KruskalWallis, que permite a comparação de resultados de mais de duas amostras independentes. Os resultados obtidos demonstraram não haver diferenças significativas entre o desempenho ortográfico dos participantes por turma $\left[X^{2}(2\right.$, $N=72)=0,185 ; p=0,912]$.

Em relação às produções textuais, o Teste Kruskal Wallis indicou que não houve diferenças significativas no que se refere ao desempenho das três séries em nenhuma das situações pesquisadas, ou seja, tanto na produção livre $\left[X^{2}\right.$ $(2, N=72)=1,918 ; p=0,383]$, quanto na produção a partir de figuras $\left[X^{2}(2, N=72)=4,403 ; p=0,111\right]$ e também no reconto $\left[X^{2}(2, N=72)=3,769 ; p=0,152\right]$.

Analisando-se os erros ortográficos cometidos no ditado (TDE), observou-se um total de 816 erros em 72 ditados (2.448 palavras escritas). A classificação dos erros, de acordo com a frequência observada em cada categoria, foi a seguinte: $21,8 \%$ por representação múltipla; $19,7 \%$ por regra contextual; $13,4 \%$ por troca de letra; $7,4 \%$ por ausência de letra; $6,9 \%$ por acréscimo de letra; $6,5 \%$ por transcrição da fala; $6,3 \%$ por troca de letra surda/sonora; $6 \%$ por sílaba complexa; $5,3 \%$ por "outros", $5,1 \%$ por supercorreção e $1,7 \%$ por marcação da nasalização.

Somando todas as palavras escritas corretamente por todos os alunos (1872 palavras) e dividindo pelo total de participantes (72), foi obtida uma pontuação média de 26 palavras escritas corretamente. Isso significa que, em média e, de acordo com as normas do TDE (Stein, 1994), esses alunos podem ser classificados como apresentando níveis

Tabela 1. Frequência de Textos Produzidos em Cada Categoria, de Acordo com as Situações de Produção

\begin{tabular}{cccll}
\hline Categoria & $\begin{array}{c}\text { Produção } \\
\text { livre }\end{array}$ & $\begin{array}{c}\text { Produção } \\
\text { figuras }\end{array}$ & $\begin{array}{c}\text { Produção } \\
\text { reconto }\end{array}$ & Total \\
\hline I & $10(14 \%)$ & $09(13 \%)$ & $01(01 \%)$ & $20(09 \%)$ \\
II & $05(07 \%)$ & $06(08 \%)$ & $08(11 \%)$ & $19(09 \%)$ \\
III & $14(19 \%)$ & $09(12 \%)$ & $11(15 \%)$ & $34(16 \%)$ \\
IV & $20(28 \%)$ & $13(18 \%)$ & $12(17 \%)$ & $45(21 \%)$ \\
V & $17(24 \%)$ & $13(18 \%)$ & $20(28 \%)$ & $50(23 \%)$ \\
VI & $06(08 \%)$ & $22(31 \%)$ & $20(28 \%)$ & $48(22 \%)$ \\
Total & $72(100 \%)$ & $72(100 \%)$ & $72(100 \%)$ & $216(100 \%)$ \\
\hline
\end{tabular}

de desempenho ortográfico inferiores ao esperado para seu nível de escolaridade.

No que se refere aos dados de produção textual, a Tabela 1 contém a quantidade de textos produzidos em cada categoria, de acordo com a situação de produção - livre, sequência de figuras ou reconto. Observa-se que, na produção livre, há uma quantidade maior de produções na categoria IV e uma menor frequência nas categorias II e VI; na produção por meio da sequência de figuras, a maior concentração está na categoria VI e a menor na categoria II; na produção reconto, os textos mais frequentes foram os mais elaborados, presentes nas categorias V e VI e a menor concentração foi encontrada na categoria I, constituindo-se somente de uma única produção.

Analisando os dados da Tabela 1 é possível perceber que, de modo geral, predominaram, na amostra estudada, produções de texto nas categorias IV, V e VI, o que já era esperado, visto tratar-se de alunos do último ano do ciclo I do Ensino Fundamental. Entretanto, a relativamente alta incidência de textos classificados nas categorias I, II e III em alunos desse nível de ensino não deixa de ser preocupante.

Utilizando-se o Teste de Friedman, que permite comparar dados amostrais relacionados, foi testada a hipótese da existência de diferença significativa entre as produções de texto elaboradas nas três situações propostas, com o objetivo de verificar se alguma(s) delas favoreceria(m) a redação de textos narrativos mais elaborados. Os resultados indicaram a existência de diferenças significativas na qualidade dos textos produzidos nas três situações $\left[X^{2}(2, N=72)=13,992\right.$; $p=0,001]$, sendo a produção livre a que obteve, em média, menores pontuações, enquanto o reconto atingiu a maior média, tendo a produção a partir de figuras alcançado um valor intermediário. Para refinar a análise dessas diferenças, estabelecendo qual/quais delas seriam significativas, foi utilizado o Teste de Wilcoxon, que tem como objetivo comparar as médias de duas amostras relacionadas, tendo sido obtida diferença significativa apenas na comparação entre produção livre e reconto $(Z=-3,839 ; p<0,001)$.

Para verificar se haveria relação entre o desempenho ortográfico e a habilidade de produção textual foi utilizado o Teste de Correlação de Spearman. Na Tabela 2, são observados os resultados do teste, os quais indicam correlações significativas entre o desempenho ortográfico e as três diferentes situações de produção de texto, sendo que essas correlações mostraram-se moderadas na situação de escrita por meio do reconto e da sequência de figuras e mais fracas na situação de produção livre. Diante desses resultados, buscou-se uma análise mais detalhada dos tipos de erros ortográficos apresentados nas produções textuais, a fim de verificar se as crianças que produzem textos estruturalmente mais elaborados são as mesmas que cometem menos erros ortográficos e de que tipo, ou seja, se há diferença entre os erros cometidos pelas crianças com maiores e menores habilidades de produção textual.

Para essa análise, optou-se por trabalhar com dois grupos: o Grupo 1 (G1) definido como grupo com baixa habilidade de produção textual, foi composto pelos alunos que tiveram todas as suas produções classificadas nas categorias I (nãohistórias) e/ou II (introdução da cena e/ou personagens), incluindo também a categoria III (além da introdução da cena 
e dos personagens há o relato de uma ação que sugere um esboço de uma situação-problema) se pelo menos uma das três produções (livre, figuras e reconto) fossem categorizadas entre I ou II, contabilizando um total de oito alunos. O Grupo 2 (G2), definido como grupo com alta habilidade de produção textual, foi composto por 12 alunos, os quais tiveram todas

Tabela 2. Correlações de Spearman (rs) entre as Diferentes Medidas de Desempenho Ortográfico e Produção Textual

\begin{tabular}{llccccc}
\hline & & $\begin{array}{c}\text { Prod. } \\
\text { Livre }\end{array}$ & $\begin{array}{c}\text { Prod. } \\
\text { Figuras }\end{array}$ & $\begin{array}{c}\text { Prod. } \\
\text { Reconto }\end{array}$ & $\begin{array}{c}\text { Total de } \\
\text { erros } \\
\text { ortográficos }\end{array}$ & $\begin{array}{c}\text { Total } \\
\text { acertos }\end{array}$ \\
\hline Prod. Livre & $\mathrm{r}_{\mathrm{s}}$ & 1,000 & 0,329 & 0,407 & $-0,281$ & 0,311 \\
& $\mathrm{p}$ & - & 0,005 & 0,000 & 0,017 & 0,008 \\
& $\mathrm{~N}$ & 72 & 72 & 72 & 72 & 72 \\
Prod. Figuras & $\mathrm{r}_{\mathrm{s}}$ & & 1,000 & 0,569 & $-0,521$ & 0,486 \\
& $\mathrm{p}$ & & - & 0,000 & 0,000 & 0,000 \\
Prod. Reconto & $\mathrm{N}$ & & 72 & 72 & 72 & 72 \\
& $\mathrm{r}_{\mathrm{s}}$ & & & 1,000 & $-0,501$ & 0,517 \\
& $\mathrm{p}$ & & & - & 0,000 & 0,000 \\
Total de erros & $\mathrm{N}$ & & & 72 & 72 & 72 \\
ortográficos & $\mathrm{r}_{\mathrm{s}}$ & & & & 1,000 & $-0,972$ \\
& $\mathrm{p}$ & & & & - & 0,000 \\
& $\mathrm{~N}$ & & & & 72 & 72 \\
Total acertos & $\mathrm{r}_{\mathrm{s}}$ & & & & & 1,000 \\
& $\mathrm{p}$ & & & & & - \\
& $\mathrm{N}$ & & & & & 72 \\
\hline
\end{tabular}

as suas produções classificadas nas categorias V (histórias quase completas) e/ou VI (histórias completas).

Como os textos variavam em quantidade de palavras, foi realizada uma ponderação, dividindo-se o total de erros pelo total de palavras escritas. Os erros ortográficos das produções foram julgados por dois juízes independentes, alcançando $90 \%$ de concordância; os $10 \%$ restantes foram avaliados conjuntamente pelos juízes, obtendo-se consenso.

Inicialmente a tipologia utilizada para a análise dos erros ortográficos nas produções textuais foi a mesma utilizada na correção do TDE, porém, como esses erros são agora observados em uma estrutura textual, tornou-se necessário o acréscimo de três categorias, a saber: (a) hipersegmentação: palavras que sofrem separação indevida, como a miga (amiga), a gora (agora); (b) hipossegmentação: palavras que sofrem junção indevida, como porisso (por isso), siperder (se perder); (c) erros gramaticais: enunciados em que não há concordância singular/plural como em "os menino", ou concordância verbal em termos de pessoa, como "eles foi", ou de tempo, como no caso das terminações ÃO (futuro) e AM (passado).

Primeiramente, foram realizadas análises para verificar se havia diferença significava entre os grupos G1 e G2 em relação ao total de erros ortográficos. Para isso, foi utilizado o teste não paramétrico de Mann-Whitney, o qual permite a comparação de duas amostras independentes, cujos resultados indicaram uma diferença significativa entre os grupos nas três situações de produção: tema livre $(U=-3,240 ; p=0,001)$; sequência de figuras $(U=-2,933$; $p=0,003)$ e reconto $(U=-2,777 ; \mathrm{p}=0,005)$. Verificou-se, portanto, que a diferença obtida entre G1 e G2 diz respeito às três situações de produção de texto, indistintamente, indicando que, em todas elas, as crianças do G1 (baixa competência na produção textual) obtiveram frequência de erros ortográficos significativamente superior aos alunos do G2 (alta competência na produção textual).

O próximo passo foi aplicar aos dados o Teste de Friedman, com o objetivo de verificar se, em alguma(s) $\mathrm{da}(\mathrm{s})$ situações de produções, haveria uma média maior de erros ortográficos. Os resultados indicaram a inexistência de diferenças significativas na quantidade de erros cometidos nas três situações de produção, tanto pelo $\mathrm{G} 1\left[X^{2}(2, N=8)\right.$ $=1,750 ; p=0,417]$ quanto pelo $\mathrm{G} 2\left[X^{2}(2, N=12)=1,636\right.$; $p=0,441]$. Esses dados sugerem que, de modo geral, a condição de produção não afetou o desempenho ortográfico, pelo menos em termos da quantidade de erros produzidos.

Foi realizada também uma análise comparativa mais detalhada dos diferentes tipos de erros ortográficos cometidos por esses participantes, em função da situação de produção de texto, a fim de observar se alguma delas favoreceria mais algum tipo de transgressão ortográfica. Para tanto, aplicouse o Teste de Friedman para analisar a quantidade de erros ortográficos cometidos em cada categoria, comparando as três situações de produção: livre, a partir de figuras e reconto. Nessa comparação, a única categoria de erros a atingir significância estatística foi "representação múltipla", sendo que, nessa categoria, a situação "reconto" foi a que apresentou uma frequência de erros significativamente superior às demais situações $\left[X^{2}(2, N=20)=6,000 ; p=0,050\right]$.

Posteriormente, foi realizado o Teste de Mann-Whitney, para verificar em quais tipos de erros a diferença entre os grupos (G1 x G2) atingiu a significância estatística. Na produção livre, os erros que alcançaram significância estatística foram erro gramatical $(U=-2,354 ; p=0,019)$ e transcrição da fala $(U=-3,074 ; p=0,002)$; na produção a partir de figuras, foram hipersegmentação $(U=-2,231$; $p=0,026)$, sílaba complexa $(U=-2,649 ; p=0,008)$ e transcrição da fala $(U=-2,601 ; p=0,009)$; na produção reconto, foram erro gramatical $(U=-3,074 ; p=0,002)$, representação múltipla $(U=-2,164 ; p=0,031)$, supercorreção $(U=-2,221 ; p=0,026)$, transcrição da fala $(U=-3,428 ; p=0,001)$ e troca de letra $(U=-2,347 ; p=0,019)$, sempre com o G1 produzindo maior número de erros do que G2.

\section{Discussão}

O principal objetivo da pesquisa foi verificar a relação entre conhecimento ortográfico e habilidades de produção textual. A partir de várias análises, verificou-se que os alunos que cometem mais erros ortográficos tendem a produzir textos estruturalmente menos elaborados. Esse resultado vai ao encontro daqueles obtidos por Connelly et al. (2012), os quais sugerem que as habilidades ortográficas desempenham, juntamente com as habilidades de linguagem oral e a memória de trabalho, importante papel na qualidade da produção dos textos escritos. O padrão de correlações significativas obtidas entre o desempenho no ditado do TDE (ortografia) e a qualidade dos textos escritos nas três situações de produção (livre, a partir de figuras e reescrita 
de texto) foi confirmado quando se compararam os erros ortográficos cometidos na escrita dos textos entre os grupos com maior e menor habilidade de produção textual, visto que as crianças que produziram textos mais elaborados em todas as situações de produção tenderam a cometer menos erros ortográficos. Esse fato nos permite levantar a hipótese de que as dúvidas na escrita de determinadas palavras podem interferir na produção textual, fazendo com que o aluno direcione os seus recursos cognitivos (atenção, memória) para pensar em como grafar essas palavras, produzindo muitas vezes textos "pobres", pois sobram menos recursos para dedicar à elaboração de textos estruturalmente completos e compreensíveis. É preciso considerar, entretanto, que tais dados não indicam uma relação causal entre as habilidades de escrita avaliadas, uma vez que é possível pensar em outras variáveis, como o nível intelectual ou o grau de escolaridade, por exemplo, que poderiam explicar as associações encontradas entre essas habilidades.

Em relação aos tipos de erros ortográficos encontrados no TDE, foi observado que a maioria deles insere-se nas categorias denominadas representação múltipla e regra contextual, o que denota uma dificuldade na compreensão das regularidades mais complexas da ortografia, como aquelas relativas a motivações contextuais e morfossintáticas. Por outro lado, observa-se também certa precariedade no domínio do sistema ortográfico, mesmo em seus aspectos mais regulares, uma vez que as categorias que expressam esse domínio (troca, ausência e acréscimo de letras, sílabas complexas, nasalização e outros) foram responsáveis por $47 \%$ dos erros identificados. Tais resultados justificam maior preocupação com o ensino sistemático da ortografia, principalmente quando comparados aos dados normativos do TDE.

Para Guimarães (2005), os erros por troca, ausência ou acréscimo de letra e nasalização podem ser um indício de dificuldades na análise fonológica das palavras, ou seja, os alunos não conseguem distinguir e representar, em suas escritas, todos os sons que compõem as palavras. Quando se fala, não é necessário refletir som por som para a reprodução das palavras, já na escrita, pelo menos em sua fase inicial, a criança precisa identificar, na própria fala, os sons que compõem as palavras, bem como a ordem sequencial dos mesmos para poder representá-los adequadamente através das letras (Zorzi, 2003). Dessa forma, foi observado que muitos alunos, mesmo possuindo uma escrita alfabética, ainda cometem erros ortográficos elementares, resultado esse que vai ao encontro da discussão realizada por Morais (2012), quando comenta que a fase alfabética não é o ponto de chegada para a escrita correta das palavras, já que o sistema ortográfico será o próximo desafio a ser compreendido e dominado.

Por outro lado, no caso das dificuldades com as representações múltiplas, categoria de erros mais frequente na amostra estudada, é possível pensar em estratégias pedagógicas que visem à compreensão da estrutura morfossintática da língua, de modo a minimizar a incidência de tais dificuldades. De acordo com Morais (2008), aprender ortografia não é somente uma questão de memória, decorar sua forma correta, pois a maior parte das correspondências letra-som são regulares, de forma que podem ser aprendidas pela compreensão. Entretanto há também irregularidades e estas exigem a memorização e/ou a utilização de dicionário. No caso das regularidades morfológico-gramaticais, as regras envolvem os morfemas, indicando a "família" ou a classe gramatical, tanto na formação de palavras derivadas como na flexão dos verbos, permitindo que a criança infira um princípio gerativo, compreendendo que determinadas partes das palavras são constantes, assim sendo, a memorização de uma a uma das formas ortográficas torna-se dispensável.

A análise dos erros ortográficos cometidos nas diferentes situações de produção demonstrou que, independente do contexto de produção textual, os alunos que apresentam produções menos elaboradas tendem a cometer mais erros ortográficos. Esse resultado vai ao encontro do estudo realizado por Souza e Correa (2007), o qual buscou examinar se, na reprodução escrita de uma história já conhecida, a criança teria um melhor desempenho ortográfico do que na escrita de uma produção espontânea, já que, por ser um texto conhecido, haveria menor preocupação com a coerência textual, restando maior atenção para ser dedicada à ortografia. Após a análise das produções, as autoras verificaram que não houve diferença significativa na proporção das transgressões ortográficas feitas pelas crianças nos dois contextos de produção, o que foi corroborado pelos resultados desta pesquisa. Pode-se levantar a hipótese de que, tanto a produção livre quanto o reconto, oferecem desafios e demandam recursos cognitivos importantes no que se refere às habilidades de escrita ortográfica, porém de ordens diferentes. Se, por um lado, a produção livre demanda maior atenção à elaboração do texto (o que pode levar o autor a dedicar menor atenção à ortografia), por outro, o reconto exige um maior domínio na escrita de palavras menos frequentes e que podem, por esse motivo, oferecer maior dificuldade ortográfica. Um exemplo foi o reconto proposto nesta pesquisa, que demandava que a criança escrevesse palavras que apresentam dificuldades relacionadas às representações múltiplas, como "lobisomem" e "cemitério".

Entretanto, analisando-se qualitativamente o tipo de erro cometido corroboraram-se os resultados de Souza e Correa (2007) ao encontrar-se, nesta pesquisa, maior frequência de erros por representação múltipla (que corresponde às categorias de irregularidades e regularidades morfossintáticas), na situação de produção de texto baseada no reconto, o que vem reforçar a hipótese de que, nessa condição, a criança se depara com a necessidade de escrever palavras de maior complexidade ortográfica, o que não ocorre quando tem a chance de escolher livremente as palavras a serem usadas. Salvo essa categoria, os resultados indicam que crianças com dificuldades na ortografia, mesmo quando tem possibilidade de escolherem as palavras que lhes são mais familiares, na produção livre, por exemplo, tendem a errar. Erram ao grafar palavras familiares, bem como palavras regulares que não deveriam comportar mais dúvidas em relação a sua forma ortográfica, como indicam as transgressões baseadas em dificuldades na análise das correspondências grafofonêmicas (erros por ausência, acréscimo e troca de letras, bem como nas sílabas complexas).

Quanto à comparação dos tipos de erros ortográficos cometidos pelos alunos com baixo (G1) e elevado (G2) domínio da produção de textos narrativos, observa-se que, 
no G2, predominam erros de representações múltiplas, sobretudo na produção livre e no reconto, o que denota uma etapa mais avançada da apropriação do conhecimento ortográfico, na qual as dificuldades que permanecem são aquelas mais difíceis de serem superadas, pois dizem respeito às irregularidades da escrita (muitas vezes devidas a razões etimológicas) ou mesmo à falta de domínio de regras ortográficas baseadas em análises morfossintáticas da língua.

Já no G1, observa-se a ocorrência mais elevada de erros por transcrição da fala, atingindo a significância estatística quando comparada ao G2 em todas as três produções (livre, figuras e reconto). Se somarmos a esse tipo de erro os erros gramaticais, já que em várias escritas essa transgressão se aproxima à maneira coloquial da fala, tem-se um predomínio da indiferenciação entre fala e escrita. Esse aspecto pode estar relacionado também à variante linguística utilizada pelos alunos pesquisados, podendo-se levantar a hipótese de que se trata de crianças que dominam padrões linguísticos mais distantes da norma culta, possivelmente devido à sua origem socioeconômica. Outras dificuldades que se mostraram significativamente maiores neste grupo (G1), pelo menos em algumas das situações de produção, foram com relação à grafia das sílabas complexas e à troca de letras, aspectos esses também mais básicos no que se refere ao domínio do sistema ortográfico.

Em resumo, é possível afirmar que os resultados evidenciaram a relação entre conhecimento ortográfico e habilidades de produção textual, não apenas do ponto de vista quantitativo, mas também qualitativo, pois foram encontrados textos menos elaborados com erros mais elementares e textos mais elaborados com maior proporção de erros relacionados a irregularidades (etimologia) ou a regularidades morfossintáticas. No entanto, o delineamento adotado não nos permite avançar muito sobre a direção dessa relação em termos de causa e efeito, o que constitui uma limitação do presente estudo.

Quando a análise foi direcionada à qualidade formal das produções textuais obtidas em diferentes contextos, os resultados mostraram que o oferecimento de apoio aos alunos, sobretudo verbal, favoreceu a produção de textos narrativos mais elaborados. Esse resultado pode ser explicado, no caso da reescrita da história ouvida anteriormente, pelo fato de que, nessa situação, a criança reproduz não apenas o conteúdo, mas também a estrutura linguística do texto que serve de modelo, reforçando a ideia de que a experiência com textos pode desempenhar papel fundamental na aquisição de um "esquema narrativo" (Lins e Silva \& Spinillo, 2000). Assim, o reconto, por já oferecer uma estrutura narrativa pronta, facilita a produção do texto, tendo o aluno a tarefa de reelaborar a história lida seguindo os padrões de coesão e coerência textual. Nesse sentido, produções livres são mais complexas de serem feitas, visto que os alunos, além de se preocupar com a coesão e coerência textual, devem selecionar e ordenar as suas ideias, precisam ter domínio sobre o que vão escrever, ou seja, refletir sobre o conteúdo, além de estruturarem seus textos a partir dos padrões do gênero exigido.

Por outro lado, a sequência de figuras oferece um apoio visual, além de sugerir elementos que constituem um enredo narrativo, como cena, personagens, situação-problema, tendo o aluno que elaborar a estrutura. As produções realizadas podem ser classificadas em níveis de complexidade em termos da exigência de sua elaboração, partindo de uma produção totalmente livre, sendo o aluno o responsável por todas as etapas de sua realização, a uma produção direcionada, a partir de modelos oferecidos. Apesar disso, não foram encontradas diferenças significativas na elaboração dos textos produzidos a partir das figuras, tanto em relação às produções livres quanto em relação aos textos produzidos por meio do reconto da história, tendo os resultados indicado, entretanto, diferenças significativas a favor do reconto quando comparado à situação da produção livre. De todo modo e corroborando resultados de pesquisas anteriores (Lins e Silva \& Spinillo, 2000; Pessoa et al., 2010), os resultados obtidos mostraram que o auxílio de apoios pode ajudar na produção de textos narrativos mais elaborados, favorecendo o trabalho com a estrutura narrativa pelo professor. No entanto, há diferenças em função do tipo de apoio oferecido, sendo que o apoio oral (reconto) parece ser o mais eficaz no sentido de favorecer a escrita de textos mais completos e elaborados. Percebe-se também que, apesar de os participantes desse estudo serem da mesma série e quase todos da mesma idade, há diferentes níveis no domínio do esquema narrativo entre eles, o que demonstra que outros aspectos podem estar envolvidos no momento de uma produção, como experiência e contato com textos, frequência de leitura, capacidade de organização das ideias e conteúdos, além do próprio conhecimento metatextual sobre os componentes necessários para a constituição de um texto narrativo.

Para Ferreira e Spinillo (2003), criar situações de intervenção metatextual, as quais levem as crianças a refletir de forma explícita e deliberada sobre a estrutura do texto, ou seja, seus componentes, organização hierárquica e convenções linguísticas, favorece o desenvolvimento da habilidade de produção de histórias. No caso dos resultados obtidos, foi possível verificar que, quando foi solicitado às crianças trabalhar sobre uma estrutura pronta, suas produções obtiveram as maiores pontuações, demonstrando que essas se beneficiam quando lhes é oferecido um modelo que evidencia as partes que compõem o texto. Torna-se necessária, porém, uma maior reflexão sobre o mesmo, uma análise metatextual, que permita a explicitação e a tomada de consciência desses conhecimentos, de modo a poder utilizálos intencionalmente para a realização de produções livres, elaboradas e estruturadas.

Os resultados obtidos, indicando maior grau de elaboração dos textos produzidos a partir do reconto quando comparados à produção livre, também vão ao encontro daqueles obtidos por Pessoa et al. (2010), sendo possível levantar a hipótese de que as crianças que escrevem textos narrativos bem elaborados nas três situações têm maior nível de consciência metatextual, sendo capazes de refletir e controlar conscientemente a elaboração dos textos em função de conhecimentos explícitos sobre a estrutura narrativa de histórias, podendo aplicá-los intencionalmente, mesmo na ausência de um apoio visual ou auditivo. Entretanto, para testar essa hipótese são necessários estudos que controlem também o conhecimento explícito dos alunos sobre a estrutura do gênero narrativo, o que não foi feito na presente pesquisa. 


\section{Considerações Finais}

A complexidade do próprio sistema ortográfico é um dos aspectos que justifica os erros cometidos pelos alunos, porém o tipo e a frequência dos mesmos permitem-nos questionar a aprendizagem (e consequentemente também o ensino) da ortografia, principalmente por se tratar de alunos do último ano do primeiro ciclo do ensino fundamental. Os resultados obtidos apontam para a necessidade de mudanças no ensino da ortografia, que estimulem a aprendizagem das regras ortográficas, já que as mesmas envolvem raciocínio, compreensão e reflexão. Nesse sentido, tal ensino deveria incluir também atenção às habilidades metalinguísticas relacionadas à consciência fonológica e morfossintática. $\mathrm{O}$ ensino da ortografia deve ser oferecido de forma sistemática, visto o caráter convencional do sistema. Dessa forma, devese considerar que o aluno, sozinho, não o descobre. Há regras que precisam ser ensinadas, discutidas e não simplesmente treinadas por meio de alguns tipos de exercícios que pouco contribuem para a aprendizagem do sistema ortográfico.

Outra possível forma de apreensão dos conhecimentos ortográficos é por meio da leitura constante de bons materiais impressos, como defende Morais (2008), visto que os mesmos são fonte alimentadora para a aprendizagem implícita, possibilitando o desenvolvimento da competência ortográfica, juntamente com situações de ensino, as quais promovam sua aprendizagem explícita, a partir da reflexão sobre as regras ortográficas, bem como sobre aspectos fonológicos, morfológicos e sintáticos da língua. Ainda com relação à leitura, é importante salientar que esta, além de possibilitar certo domínio sobre os conhecimentos ortográficos, propicia elementos informacionais e estruturais a serem utilizados na elaboração de produções textuais. Nesse aspecto, também as práticas educativas que levem o aluno a refletir deliberadamente sobre a estrutura dos diferentes gêneros textuais parecem ser uma opção importante, pois a literatura tem evidenciado a relação entre o desenvolvimento das habilidades metatextuais e as habilidades de produção de texto.

Os resultados obtidos nesta pesquisa parecem sustentar a hipótese de que o ensino adequado da ortografia, indiretamente, pode contribuir para o desenvolvimento das habilidades de produção de texto, reforçando a ideia de uma escolarização que se mostre atenta às relações entre alfabetização e letramento. Espera-se que o aluno produza bons textos, tanto de acordo com a estrutura do gênero a ser desenvolvido, como em sua grafia, já que é por meio da grafia correta que um texto pode ser compartilhado e compreendido entre os vários dialetos falados. Espera-se também que esse texto possa ser produzido independente do contexto, por isso uma boa alternativa pedagógica seria propiciar o desenvolvimento da consciência metatextual, pois quanto maior o nível de consciência sobre a estrutura e organização de gênero textual, mais coerente e coesa será sua produção. Nesse aspecto, apoios - como figuras sugerindo uma sequência narrativa, bem como histórias conhecidas ou lidas anteriormente - podem ser utilizados como estímulo e modelo. Acredita-se que as habilidades ortográficas e as de produção textual estão relacionadas, mas cada uma com suas peculiaridades, por esse motivo merecem um ensino sistemático e específico.

\section{Referências}

Albuquerque, E. B. C., \& Spinillo, A. G. (1998). Consciência textual em crianças: Critérios adotados na identificação de partes de textos. Revista de Estudios e Investigación en Psicología y Educación, 3(2), 145-158.

Babayigit, S., \& Stainthorp, R. (2011). Modeling the relationships between cognitive-linguistic skills and literacy skills: New insights from a transparent orthography. Journal of Educational Psychology, 103(1), 169-189.

Barrera, S., \& Maluf, M. R. (2003) Consciência metalingüística e alfabetização: Um estudo com crianças da primeira série do ensino fundamental. Psicologia: Reflexão e Crítica, 16(3), 491-502.

Barrera, S. D., \& Nobile, G. G. (2010). Conhecimento ortográfico, compreensão em leitura e competências de produção textual em alunos com dificuldades no processo de escolarização. In S. R. K. Guimarães \& M. R. Maluf (Orgs.), Aprendizagem da Linguagem Escrita: Contribuições da pesquisa (pp. 203-238). São Paulo: Vetor.

Berman, R.A. (2008). The psycholinguistics of developing text construction. Journal of Child Language, 35(4), 735-771.

Carraher, T.N. (1985). Explorações sobre o desenvolvimento da competência em ortografia em português. Psicologia: Teoria e Pesquisa, 3(1), 269-285.

Connelly, V., Dockrell, J. E., Walter, K., \& Critten, S. (2012). Predicting the quality of composition and written language bursts from oral language, spelling and handwriting skills in children with and without specific language impairment. Written Communication, 29(3), 278-302.

Correa, J. (2009). Habilidades metalinguísticas relacionadas à sintaxe e à morfologia. In M. da Mota (Org.), Desenvolvimento Metalinguístico: Questões contemporâneas (pp.55-76). São Paulo: Casa do Psicólogo.

Ferreira, A. L., \& Spinillo, A. G. (2003). Desenvolvendo a habilidade de produção de textos em crianças a partir da consciência metatextual. In M. R. Maluf(Org.), Metalinguagem e aquisição da escrita: Contribuições da pesquisa para a prática da Alfabetização (pp. 119-148). São Paulo: Casa do Psicólogo.

Gombert, J. E. (1992). Metalinguistic development. Harvester: Wheatsheaf.

Guimarães, S. R. K. (2003). O aperfeiçoamento da concepção alfabética de escrita: relação entre consciência fonológica e representações ortográficas. In M.R. Maluf (Org.), Metalinguagem e aquisição da escrita: Contribuições da pesquisa para a prática da alfabetização (pp.149-184). São. Paulo: Casa do Psicólogo.

Guimarães, S. R. K. (2005). Aprendizagem da leitura e da escrita: O papel das habilidades metalinguísticas. São Paulo: Vetor.

Leal, T. F., \& Roazzi, A. (2007). A criança pensa...e aprende ortografia. In A. G. de Morais (Org.), O aprendizado da ortografia (3a ed., pp. 99-120). Belo Horizonte: Autêntica.

Lins e Silva, M. E., \& Spinillo, A. G. (2000). A influência de diferentes situações de produção na escrita de histórias. Psicologia: Reflexão e Crítica, 13(3), 337-350.

Maluf, M. R., \& Cardoso-Martins, C. (2013). Alfabetização no século XXI: Como se aprende a ler e a escrever. Porto Alegre: Penso. 
Maluf, M. R., \& Gombert, J. E. (2008). Habilidades implícitas e controle cognitivo na aprendizagem da linguagem escrita. In M. R. Maluf \& S. R. K. Guimarães (Orgs.), Desenvolvimento da linguagem oral e escrita (pp.123-135). Curitiba: Editora UFPR.

Morais, A. G. (2012). Sistema de escrita alfabética. São Paulo: Melhoramentos.

Morais, A. G. (2007a). Ortografia: Este peculiar objeto de conhecimento. In A. G. de Morais (Org.), O aprendizado da ortografia (3a ed., pp. 7-19). Belo Horizonte:Autêntica.

Morais, A. G. (2007b). "Por que gozado não se escreve com u no final?" - os conhecimentos explícitos verbais da criança sobre a ortografia. In A. G. de Morais (Org.), O aprendizado da ortografia (3a ed., pp. 77-98). Belo Horizonte: Autêntica.

Morais, A. G. (2008). Ortografia: Ensinar e aprender. São Paulo: Editora Ática.

Morais, J., Leite, I., \& Kolinsky, R. (2013). Entre a pré-leitura e a leitura hábil: Condições e patamares da aprendizagem. In M. R. Maluf \& C. Cardoso-Martins (Orgs.), Alfabetização no século XXI: Como se aprende a ler e a escrever (pp. 17-48). Porto Alegre: Penso.

Nunes, T. (1992). Leitura e escrita: Processos e desenvolvimento. In E. M. S. S. Alencar (Org.), Novas contribuições da psicologia aos processos de ensino e aprendizagem (pp.13-49). São Paulo: Cortez.

Pessoa, A. P., Correa, J., \& Spinillo, A. G. (2010). Contexto de produção e o estabelecimento da coerência na escrita de histórias por crianças. Psicologia: Reflexão e Crítica, 23(2), 253-260.
Queiroga, B. A. M., Lins, M. B., \& Pereira, M. A. L. V. (2006). Conhecimento morfossintático e ortografia em crianças do ensino fundamental. Psicologia: Teoria e Pesquisa, 22(1), 95-99.

Rego, L. L. B., \& Buarque, L. L. (1997). Consciência sintática, consciência fonológica e aquisição de regras ortográficas. Psicologia: Reflexão e Crítica, 10(2), 199-217.

Rego, L. L. B., \& Buarque, L. L. (2007). Algumas fontes de dificuldade na aprendizagem de regras ortográficas. In A.G. de Morais (Org.), O aprendizado da ortografia (3a ed., pp. 21-41). Belo Horizonte: Autêntica.

Santos, M. J., \& Barrera, S. D. (2012). Relações entre conhecimento explícito da ortografia e desempenho ortográfico. Revista Semestral da Associação Brasileira de Psicologia Escolar e Educacional, 16(2), 257-263.

Souza, A. C. F. C., \& Correa, J. (2007). Reprodução escrita de histórias e a escrita ortográfica de crianças. Psicologia em Pesquisa (UFRJ), 1(02), 32-40.

Spinillo, A. G., \& Martins, R. A. (1997). Uma análise da produção de histórias coerentes por crianças. Psicologia: Reflexão $e$ Crítica, 10(2), 219-248.

Spinillo, A. G. (2009) A consciência metatextual. In M. da Mota (Org.), Desenvolvimento metalinguístico: Questões contemporâneas (pp.77-113). São Paulo: Casa do Psicólogo.

Stein, L.M. (1994). TDE: Teste de desempenho escolar: manual para aplicação e interpretação. São Paulo: Casa do Psicólogo.

Zorzi, J. L. (1998). Aprender a escrever: A apropriação do sistema ortográfico. Porto Alegre: Artmed.

Zorzi, J. L. (2003). Aprendizagem e distúrbios da linguagem escrita. Porto Alegre: Artmed.

Recebido em 04.12.2013

Primeira decisão editorial em 17.03.2015

Versão final em 19.03.2015

Aceito em 08.06.2015 